\title{
Da violência epistemológica a epistemologias próprias: experiências de narrativas com mulheres cis periféricas, mulheres trans e travestis
}

\author{
From epistemological violence to own epistemologies: narrative \\ experiences with peripheral cis women, trans women and transvestite
}

Laiz Maria Silva Chohfiי, Jailton Bezerra Melo', Paola Alves de Souza1

DOI: 10.1590/0103-11042021E102

\begin{abstract}
RESUMO Este artigo apresenta compreensão de problemáticas enfrentadas por mulheres cis periféricas, mulheres trans e travestis na construção de epistemologias próprias no campo das ciências. Para tal, baseia-se no campo construído por três teses de doutorado, cujos autores são os mesmos deste artigo. As teses, embora não tenham como foco principal e central o mesmo do presente artigo, evidenciam, a partir do campo construído, que pouco conhecimento a respeito das populações trans, travesti e periférica é produzido por seus integrantes. Identifica-se, a partir da releitura do material produzido pelos pesquisadores, a existência de trincheiras, que se interpõem no caminho percorrido por mulheres trans, travestis e mulheres cis periféricas para produzir conhecimento. São elas: a própria sobrevivência, a permanência no ensino e a validação do conhecimento produzido por corpos e existências não hegemônicas. Discute-se, por fim, que há um descompasso entre as políticas de educação vigentes e as experiências vividas, indicando uma fissura em práticas de saúde e no cuidado integral dessa população. A isso, somam-se violências e iniquidades em saúde que acabam interferindo na comunicação e na potência do saber popular como estratégia de resistência e saber científico, contrapondo-se ao saber acadêmico hegemônico.
\end{abstract}

PALAVRAS-CHAVE Mulheres. Participação da comunidade. Educação em saúde. Serviços de saúde escolar.

1 Universidade de São Paulo (USP) - São Paulo (SP),

Brasil.

laiz.chohfi@gmail.com
ABSTRACT This article presents an understanding of the problems faced by peripheral cis women, trans women, and transvestites in the construction of their own epistemologies in the field of sciences. For that, it is based on the field built by three doctoral theses, whose authors are the same as in this article. The theses, although they do not have the main focus of the present article, show, from the field constructed, that little knowledge about the trans, transvestite, and peripheral populations is produced by their members. From the re-reading of the material produced by the researchers, the existence of trenches is identified, which stand in the path taken by trans women, transvestites, and peripheral cis women to produce knowledge. The trenches are: survival, permanence at university, and the validation of knowledge produced by bodies and non-hegemonic existences. Finally, it discusses the existing mismatch between the current education policies and the experiences, indicating a fissure in health practices and in the comprehensive care of this population. In addition, we see violence and inequities in health that end up interfering in the communication and power of popular knowledge as a strategy of resistance and scientific knowledge, in contrast to hegemonic academic knowledge.

KEYWORDS Women. Community participation. Health education. School health services. 


\section{Introdução}

Apresentam-se, a partir das pesquisas de doutoramento dos autores, problemáticas enfrentadas por mulheres cis periféricas, mulheres transexuais e travestis que implicam entraves para a construção e a produção de epistemologias próprias no campo das ciências. A partir disso, identificam-se obstáculos, aqui chamados de trincheiras, que marcam essa dificuldade acerca de temáticas que lhes digam respeito.

Chama-se de 'epistemologia' a construção das subjetividades'. Como mulheres cis periféricas, mulheres transexuais e travestis se tornam o que são? Epistemologia é entendida não como um saber irrefutável, mas como uma ordem do discurso. Perpassa o saber/poder interessado, aparecendo como um dispositivo de produzir saber/poder e violência, inspirando novas estratégias pedagógicas modernas.

Como fruto dessa análise, encontram-se procedimentos de individualização de corpos: observação, classificação e organização analítica. As mulheres aqui estudadas têm as suas existências atravessadas por uma ordem do discurso vigente sobre elas. Apontar isso demonstra que pessoas trans e travestis, por exemplo, não são porque são; são porque existe um saber e uma verdade sobre elas, um poder que as gere - o que também se pode extrair acerca das dissidências que são empurradas para a periferia (geográfica e simbólica).

As três teses discutidas provêm da psicologia, tendo suas metodologias em aproximação com a filosofia, nomeadamente fenomenologia existencial (teses 2 e 3 ) e método arqueogenealógico foucaultiano (tese 1). A primeira tese que serve de campo ainda está em andamento e objetiva analisar narrativas de mulheres transexuais e travestis que passaram pelo Programa Transcidadania ${ }^{2}$, à luz do método arqueogenealógico foucaultiano. A segunda, também em construção, investiga a experiência de estudantes universitários em permanecer em uma universidade pública. Parte dessa investigação se baseia em anotações realizadas pela pesquisadora a respeito da experiência de estudantes pobres em uma universidade pública.

A terceira tese (finalizada) objetivou compreender como travestis, mulheres transexuais e homens trans demandam ação de cuidado, especialmente nos campos da saúde e da educação. Aponta para uma revisão necessária de práticas desses campos, justificada pela insuficiência de políticas públicas que partem da própria população envolvida. Ainda que as teses 2 e 3 englobem a experiência de masculinidades, neste artigo, buscou-se apenas analisar o repertório de mulheres cis periféricas, mulheres transexuais e travestis, por ser objetivo da discussão.

$\mathrm{Na}$ esteira das teses 1 e 3 acerca das experiências travestis e trans, percebe-se que as investigações evidenciadas a respeito dessa população foram produzidas por pessoas cisgênero, especialmente não Lésbicas, Gays e Bissexuais (LGB). Nesses trabalhos, algumas pesquisas partem do interesse médico nos inquéritos e achados do corpo a partir de um olhar binário para gênero ${ }^{3}$ (sistema homem-mulher), resultando em documentos que 'fiscalizam' a veracidade do gênero e formulam categorias 'sexuais' nosológicas 4 .

A compreensão teórica a respeito de gênero parte da virada de estudos brasileiros ${ }^{5,6}$. Gênero é um importante marcador social da diferença e categoria social analítica que perpassa esferas culturais, políticas e estéticas, sendo propulsor e mantenedor de estratégias de sobrevivência e fortalecimento coletivo.

Essa categoria está entrelaçada a outros marcadores sociais da diferença (raça, orientação sexual, regionalidade e classe social), o que direciona diversos lúmens na compreensão da problemática apresentada no Brasil. Assim, tal discussão passa a tomar - sobretudo pelos intercruzamentos das teses discutidas - uma direção possível de contestação do rigor científico de generalização.

Acerca da produção de conhecimento sobre a permanência estudantil, tendo as investigações publicadas nos últimos 20 anos 
no Brasil7-13, somente uma delas foi escrita por uma mulher cis jovem e periférica ${ }^{13}$. As demais foram realizadas por trabalhadoras/es da assistência estudantil, em sua maioria por assistentes sociais. Sem necessariamente compreender se tratar da mesma dificuldade ou dos mesmos entraves, nota-se, como resultado, que nem as jovens mulheres cis periféricas, que alcançam a universidade, nem as mulheres trans e travestis escrevem a respeito de suas próprias experiências.

Sobre produções que trazem a 'evasão' escolar, e que se compreendem como 'expulsão’ escolar - assunto a ser discutido posteriormente -, demarca-se também a elaboração de dados empíricos que não captam marcadores sociais da diferença. As pesquisas analisadas nas teses parecem responder muito mais a uma ordem burocrática e protocolar dos setores públicos, enquanto instituição, que a uma demanda caracterizada em diálogo com necessidades básicas de permanência escolar de mulheres transexuais e travestis, por exemplo.

Sobre a evasão universitária, por outro lado, muito já foi produzido ${ }^{14}$, em consequência da cobrança de movimentos estudantis, fóruns/ órgãos de instituições públicas federais. O Plano Nacional de Assistência Estudantil (PNAES) $^{15}$ é fruto dessas reivindicações ${ }^{9,10}$. Isso acontece, também, nas universidades estaduais: há incentivo financeiro para permanência de estudantes pobres, seja por meio da oferta de auxílios financeiros ou de serviços básicos ${ }^{9-12}$, sem cuidar do 'como' dessa permanência. Estariam as universidades preparadas para receber jovens pobres? Ou os estariam expulsando, como também faz o sistema escolar em relação às alunas trans e travestis?

Da releitura das teses, foram encontradas o que aqui se chamam trincheiras. 'Trincheira' significa 'fosso', 'escavação no solo'; 'abrigo aos combatentes'. É um lugar no qual guerras são enfrentadas, mas também é local de proteção no enfrentamento.

As combatentes aqui estudadas, para chegarem a ter possibilidade de elaborar epistemologias, acompanhando a metáfora de vencer a batalha, precisam primeiramente permanecer vivas, constituindo a primeira trincheira. Já a segunda trata da própria permanência: sobreviver e acessar o ensino não garante permanência nele. A última trincheira trata de, sobrevivendo às etapas anteriores, ter o conhecimento validado e reconhecido.

A faceta perigosa da proteção da trincheira se relaciona ao fato de que as combatentes podem não sobreviver: de saúde abalada, perecem ou são repelidas do ambiente escolar. Diferentemente do que acontece em uma batalha, guerra ou disputa de poder, a trincheira, nesse caso, oferece proteção não no agora, mas no futuro: sobrevivendo, podem prosperar. Prosperando, podem facilitar o caminho das que vierem depois. O perigo é presente, enquanto a proteção, futura.

\section{Material e métodos}

Utilizou-se, como recurso, a experiência com narrativas ${ }^{16}$, a partir da releitura e análise das três teses em questão. Narrativa será entendida como possibilidade de pôr em andamento histórias vividas e testemunhadas no caminhar da pesquisa ${ }^{\mathbf{1 6}, 17}$. Para isso, utilizaram-se três instrumentos: na pesquisa 1 , investigou-se a experiência em pesquisa/serviço com a população trans e travesti; na pesquisa 2 , discutiu-se a experiência a partir de diários de bordo da pesquisadora com mulheres cis periféricas; e na pesquisa 3 , partiu-se de relatos de experiência em entrevistas com pessoas trans e travestis. Com isso, justifica-se que esta discussão parte da experiência de quem escreve, a partir do que foi possível encontrar no campo, ou seja, da experiência própria com o material produzido.

Para o levantamento bibliográfico, retomou-se o campo das três investigações apresentadas. Recorreu-se à leitura cartográfica do material empírico ${ }^{18}$, a partir do olhar da fenomenologia existencial. Como proposta inicial, para cada tese, partiu-se de questões-bússola ${ }^{19}$, situadas da seguinte forma: 
1. Como se dão os processos de exclusão e expulsão de mulheres trans na escola, pela voz de participantes do Programa Transcidadania?

2. Como vem sendo/tem sido a experiência de permanecer na universidade por parte de seu corpo discente?

3. Como tem sido a experiência de travestis e mulheres transexuais, no que diz respeito às suas corporalidades, e quais experiências de cuidado essa população requer?

A pesquisa 1 surge a partir de evidências da pesquisa 3, tendo esta parecer do Comitê de Ética em Pesquisa (CEP) com Seres Humanos de número CAAE: 79045917.1.0000.5561. Quanto à pesquisa 2, não houve necessidade de submissão ao CEP, uma vez que ela parte de diários de bordo da pesquisadora, ainda que se saiba da impossibilidade de neutralidade em contato com o campo.

\section{Resultados e discussão}

\section{Primeira trincheira: como habitar a existência, se existir (muitas vezes) é morrer?}

Prezado leitor/a, espero que aqui já se faça um pacto de início, pois minha débil nau está em naufrágio. Poderia dar a mão a essa destemida e desconhecida navegante? Poderia ajudar-me a nadar e a não largar o barco no meio do nada? Aqui não vou falar da paz e, muito menos, da fraternidade, aqui vai ser dito sobre trincheiras, guerras, lutas e enfrentamentos que são postos para se manter vivas.

Foi na graduação que eu ouvi o termo 'identidade de gênero' a partir de estudos da sexualidade na educação $0^{5}$. De início, senti-me confusa, mas quando se tematizou sobre mulheres transexuais e os processos perversos de exclusão que sofrem socialmente, surgiu um sentimento que eu não sabia compreender ou lidar.

A cada vez que se falava dos processos de violência/estigma que essas mulheres sofrem ou sofreram na trajetória escolar, era como se escorresse sangue dos meus poros. Ao avançar na disciplina, percebia que a história era feita a partir do olhar do outro, do estranho, do estrangeiro. Ali já se anunciava uma análise sócio-histórica na educação dessas pessoas, especialmente sobre a trajetória de mulheres transexuais no ensino básico.

Em janeiro de 2015, foi lançado, na cidade de São Paulo, o Programa Transcidadania, que objetiva a elevação escolar de mulheres transexuais, travestis e homens trans expulsos/as da escola, na idade regular. Esse programa estava dentro das metas de gestão do então prefeito Fernando Haddad ${ }^{2}$. Uma das respostas à meta foi a criação da Coordenação de Políticas para LGBTI, da Secretaria de Direitos Humanos e Cidadania da Cidade de São Paulo.

É a partir das histórias de vida de travestis e mulheres transexuais desse programa que se intenta compreender os atravessamentos sócio-históricos de suas trajetórias, compartilhando de saberes populares que dialogam com a possibilidade de saber científico. Esse movimento é necessário e fundamental, na medida em que passamos a compreender que a aparição e a permanência dessas pessoas, enquanto sujeitos, na escola, dão-se em meio à revolução de seus corpos, como espaço político de suas existências, incitando epistemologias amparadas pelo saber da experiência.

A tese 1 à qual aqui se recorre encontra-se em muitos momentos com a tese 2 por entender que os marcadores da diferença por vezes se confundem, anunciando dores difíceis de serem sentidas e compreendidas. Ler a experiência de uma mulher trans branca trará uma narrativa distinta de uma mulher trans negra, por exemplo, uma vez que a raça aprofunda desigualdades e carências (especialmente da população brasileira), perpassando, inclusive, pelos abismos existentes entre o que se compreende por classe social e qual experiência se depreende desse emaranhado. 
A respeito da sobrevida da população periférica, os dados não são tão alarmantes quanto os que se referem especificamente às mulheres trans e travestis, embora não deixem de ser preocupantes. Dados fornecidos pelo Sistema de Informação de Mortalidade (SIM) do Ministério da Saúde apontam 68.242 óbitos de adolescentes e jovens adultos, com idade entre 10 e 29 anos, entre os anos 2000 e 2006 na Grande São Paulo. Destes, 36\% são de mulheres e $10 \%$ são identificadas como pardas ou negras ${ }^{20}$. Embora o maior número de mortos seja da população que se identifica como branca (57,49\%), conclui-se que as causas de morte do grupo de jovens pretas/ os e pardas/os são oriundas da violência das periferias paulistas ${ }^{21}$.

Jovens pretas/os e pardas/os são as/os maiores vítimas de morte por agressão ou violência, doenças infecciosas, parasitárias ou associadas ao sistema circulatório, além de causas externas ${ }^{22}$. Isso se deve às condições precárias a que essa população está submetida: falta de infraestrutura básica de educação, acesso à saúde e opções seguras de lazer, refletindo em inconstâncias de saúde e educação de mulheres (cis e trans).

O 'Dossiê Retratos das Desigualdades de Gênero e Raça'21, no ano de 2018, aponta que cerca de $70 \%$ dos recebedores do 'Bolsa Família’ são famílias chefiadas por pessoas negras. A renda das mulheres negras no Brasil é a mais baixa em comparação com as outras categorias. Mulheres brancas recebem, em média, $\mathrm{R} \$ 957,000$, enquanto as negras recebem $\mathrm{R} \$ 544,40$. Os dados não conferem se tais mulheres são cis ou trans - um problema nas pesquisas que dialogam com as desigualdades sociais -, demarcando a falta de sistematização de dados que apreendam índices específicos para pensar estratégias em políticas públicas.

Por sua vez, a taxa de desemprego das mulheres negras é maior em comparação com a das mulheres brancas. As mulheres negras têm taxa de desemprego de 12,5\% (do total de desempregados brasileiros), enquanto a das mulheres brancas é de 9,2\%. Cerca de 26,8\% dos lares em favelas são chefiados por mulheres negras, enquanto $12,8 \%$, por mulheres brancas. A respeito da escolaridade, a média de anos de estudos da população com 16 anos ou mais, para mulheres negras, é de 7,8 anos. Mulheres brancas têm quase 2 anos a mais: 9,7 anos em média de estudo21. Os dados não cobrem a desestruturação da educação para a população trans, com índices que demarcam não só a expulsão escolar, mas também a destemida ação violenta sobre suas experiências não normativas ${ }^{2,5}$.

Identificamos, com isso, a primeira trincheira: a própria sobrevivência na margem, na periferia. Aponta-se a necessidade de aproximação da saúde com o campo da educação, pensando na interseccionalidade das experiências dissidentes. A própria periferia oferece proteção perigosa, que é a trincheira - sempre arriscada a colapsar. Tanto para mulheres trans ou travestis quanto para aquelas cis oriundas das periferias, a possibilidade de construir ciência no Brasil é um sonho ou desejo distante.

Sobreviver aos índices não é suficiente. É necessário ainda vencer o abismo da escolaridade e de renda, em busca de construir condições para a dedicação aos estudos, imprescindível para alcançar o mundo acadêmico. Há combatentes dessa batalha que não ultrapassam esse ponto, mesmo havendo políticas públicas dedicadas a mitigar desigualdades.

\section{Segunda trincheira: a violenta permanência no espaço que expulsa - consequências para a saúde mental}

Tomando o Programa Transcidadania como uma política pública, podemos afirmar que essa construção foi se dando a partir da prática com essa população, até porque não havia, em 2015 (e ainda hoje não há), dados oficiais sobre a existência dessas vidas (ainda que a Associação Nacional de Travestis e Transexuais - Antra - se pronuncie sobre alguns dados dessa população, especialmente acerca da violência, 
apontando que, de 2008 a 2020, a média é de 122,5 assassinatos por ano ${ }^{23}$ ).

Não existem dados acerca de evasão/expulsão escolar da população trans e travesti que sejam oficiais. Porém, uma produção ${ }^{2}$ aponta que $98 \%$ da população atendida durante os 2 anos iniciais do 'Programa Transcidadania' trazia relatos da expulsão escolar desde os 11 anos de idade.

A maior parte dos estudantes de ensino médio no Brasil está em escolas públicas, totalizando cerca de $85 \%{ }^{24}$. O fato de o acesso ao ensino básico ter sido considerado como direito universal $^{25}$ e de as políticas públicas terem finalidade de expandir as redes de ensino impactam positivamente no acesso. A expansão, no entanto, não consegue garantir qualidade do ensino ou quantidade de recursos. Conforme a 'Síntese dos Indicadores Sociais'26, entre 2012 e 2017 , apenas $36 \%$ dos alunos oriundos de escolas públicas acessaram o ensino superior. Daqueles que provêm do ensino privado, 79,2\% entraram em universidades.

No que diz respeito ao acesso a universidades públicas, a situação se complica. Como exemplo, no ano de 2016, cerca de $34,6 \%$ dos ingressantes da Universidade de São Paulo (USP) provinham do sistema público de ensino ${ }^{24}$. A maior parte desses estudantes provém do ensino privado, e em alguns cursos são a esmagadora maioria. Dos alunos oriundos de escolas públicas, 34,6\% não se distribuem por igual entre os institutos que compõem essa universidade.

Ser diferente, não dominar conteúdos que colegas dominam com facilidade, não compreender exatamente o que docentes querem dizer com as palavras que utilizam são resultados encontrados na tese 2 . A seguir, apresentamos, a partir dos diários de bordo, um atendimento realizado, como ilustração do sofrimento/adoecimento de uma mulher cis negra, estudante de graduação, proveniente da periferia paulista.

Flor (nome fictício) busca atendimento individual em plantão psicológico ${ }^{27}$, pois pensava haver algo de errado consigo. Iniciou dizendo da dificuldade com a disciplina de Estatística, obrigatória no curso de ciências sociais. Dizia não conseguir aprender, sentindo que 'aquilo não era para ela'. Quando perguntada a respeito dos estudos, descreve uma rotina impossível: "Horas infinitas de estudo, sem pausa nem para comer; estudar mais que respirar, estudar mais que viver, até estafar e não se lembrar de nada". Essa era a queixa principal: não conseguir se lembrar do que estudava. Por isso imaginava que algo estava errado.

Aprofundando um pouco, Flor narrou sua experiência enquanto estudante no ensino público desde pequena e do quanto seus professores a incentivavam:

Diziam que ela era realmente muito inteligente e capaz, que deveria inclusive buscar alçar voos mais altos do que os que eram imaginados na periferia em que vivia.

Não recebia em casa o apoio que tinha na escola - e não porque seus pais não fossem amorosos e cuidadosos. Acontece que a realidade do ensino superior era distante da casa: a mãe era faxineira, e o pai, pedreiro. "Nenhum dos dois conseguia compreender o que era escolher estudar ciências sociais numa universidade pública. Para que isso serviria?”.

Na casa de Flor, ninguém entendia e podia, de maneira certeira, apoiá-la nos estudos. Ninguém lá sabia estudar 'academicamente'. O repertório construído na escola pública também não era suficiente; e, da melhor aluna da escola e de todas as suas turmas, Flor passou a se considerar "a pior". Não entendia a razão disso, afinal, "nada tinha mudado".

Nas conversas, entendemos que tudo havia mudado: do "aqui não é para mim", Flor passou a dizer "Tudo aqui me diz que eu não sou daqui". Negra e periférica, em uma turma de maioria branca, era diferente de colegas "dirigindo Citröens". Não entendia as referências que seus professores faziam "àquele museu importante que tem na França”. Tudo ali realmente não cuidava para que ela se sentisse pertencente.

Identificando essa questão, Flor entendeu o problema e, sabendo que não havia nada de errado consigo, mas com o lugar que 
não estava preparado para recebê-la, pôde fazer uma escolha: quis, a partir da busca por construir repertório para fazer daquele lugar dela também, continuar na universidade. Era isso que estava em jogo quando da procura pelo atendimento: sua permanência na universidade.

Muitas alunas buscavam atendimento por essa razão: "sou burra", "tem algo de errado comigo porque não aprendo", "não entendo o que o professor quer dizer" (tese 2). Dão a ver, em nossa perspectiva, duas principais questões. A primeira relaciona-se à construção do 'fracasso escolar'28,29.

É dessa forma que pode ser nomeado o processo a partir do qual o/a estudante é inteiramente responsabilizado/a pelas dificuldades escolares ${ }^{28}$. Desconsidera-se a responsabilidade da instituição de ensino, condições de estudo, moradia ou participação familiar nesse processo. Não se considera o deslocamento cansativo e longo e seu impacto no rendimento escolar, tampouco o tempo de estudos mais curto (somado a uma jornada diária de trabalho que, muitas vezes, não tem relação com a área de estudos). Desconsideram-se também as diferenças facilmente identificáveis com relação aos colegas de turma: cor da pele, viagens de fim de ano, saber qual é o museu "lá da França"; e, por conta disso tudo, acompanhar o conteúdo ministrado durante as aulas é outra barreira.

Conforme narram as alunas atendidas, é como se acontecesse um jogo de 'batata-quente' quando são solicitadas a falar, uma vez que, por vontade própria, se não se sentem pertencentes ao espaço, já não se voluntariam, por pensarem que 'não teriam nada a acrescentar'. Como no jogo, em que é necessário passar a 'batata' logo para frente para não se queimar, Flor e outras alunas falam o mais rápido possível para não serem notadas. Seguiam, assim, muito solitárias; carregando em suas costas o peso do fracasso.

A segunda questão percebida é que a universidade é um ambiente que expulsa. Embora existam os programas de permanência estudantil nas instituições federais e estaduais, que visam oferecer condições mínimas de permanência no ensino superior público para a população mais pobre e periférica-13, não há garantia dessa permanência, já que não há transformação do ambiente para receber essa população.

Com a saúde mental comprometida, desgastada fisicamente pelo deslocamento e por horas extenuantes de estudo, a trincheira da permanência no ensino é, com muita dificuldade, suportada e ultrapassada. Quando as combatentes perecem, considera-se como evasão escolar, ao invés de 'expulsão' escolar. Não são elas que se evadem, como que por escolha própria. São convocadas a se retirar. Questionamos: como podem, nesse sentido, chegar a produzir epistemologias?

Quando pensamos nas universidades públicas como lugar de construção de conhecimento científico de excelência, além de direcionamento de práticas interventivas em comunidades e serviços, é possível perguntar: nesse projeto de 'excelência', cabem mulheres periféricas, trans e travestis?

Na tentativa de favorecer inclusão, programas de permanência estudantil elaboram editais específicos. Se, por um lado, tais ações 'afirmativas' fazem diferença no acesso dessa população, por outro, não garantem a qualidade dessa permanência ${ }^{13}$ : o dinheiro não resolve a violência do espaço que expulsa.

Se é só 'vencendo' tudo isso que essa parcela da população pode chegar a elaborar conhecimento, enfrentando trincheiras diárias que vão desde o deslocamento precário à permanência universitária, consideramos urgentes espaços para que esses saberes possam constituir possibilidades de driblar problemáticas sociais e fazer uma escritura de uma ciência social. Aqui, pergunta-se: seria a possibilidade dessa escritura a premissa para continuar e tentar 'pular a trincheira' como o 'esforço de permanecer'?

\section{Terceira trincheira: o saber científico como violência epistemológica}

Neste ponto, partimos de análises sobre como as identidades trans passaram a ser lidas pelo 
crivo científico ${ }^{3,4,6,30}$. Sugere-se que o saber científico, oriundo especialmente de profissionais médicos que segmentam o corpo, circunscreve sintomas e caracteriza a patologia, "não serve para entender as fissuras, as diferenças, as exclusões sobrepostas de sujeitos que sempre ficaram fora do projeto de nação"6(48), produzindo violência epistemológica.

Qual saber é produzido, com qual finalidade, a serviço de quem e quais demandas que urgem dessa 'caracterização de saber'? Campos de forças teóricas das ciências clássicas buscam veracização de discursos que categorizam pessoas como sujeitos ou a-sujeitados, além de fomentar o controle e definição de paradigmas ${ }^{31}$.

O saber científico delega o estatuto de ciência como propriedade, preocupando-se com a legitimidade de técnicas e teorias que potencializariam um 'saber para o povo', e não um 'saber com o povo'. Essa validação do conhecimento enquanto científico, atrelada a epistemologias que decorrem de ideais positivistas, enclausura práticas e priva comunidades e grupos minoritários de suas próprias histórias e direitos culturais, especialmente em minorias como travestis, mulheres transexuais e mulheres cis periféricas.

O saber evidenciado por esses grupos sinaliza a fragilidade das ciências - em especial, as ciências que dialogam com a saúde pública e a educação -, rompendo a modulação de padrões de resposta para comportamentos específicos e explicações causais oriundas de determinantes sociais.

Com isso, recorreremos à narrativa de Fernanda (nome fictício, tese 3), para melhor entendermos como o 'saber do povo' constrói margens que fogem da diagramação do discurso científico:

O saber que se constrói, dentro do grupo [trans], é maior do que o externo... médico, enfermeira pode ter esse saber acadêmico, mas elas [travestis e mulheres transexuais] invadem até o saber acadêmico.
Essa narrativa localiza-se onde o poder urge: da sustentação de discursos/saberes que são provenientes do status de publicização. Tais discursos são possíveis graças à articulação de saberes produzidos pelas próprias experiências singulares, via apropriação desse poder que emana das relações e que, muitas vezes, não encontram lugar nos serviços públicos de saúde nem na escola. Ou seja, o acesso ao saber científico torna-se acesso para quem? Para onde e para quem esses discursos são direcionados?

Seguimos essa perspectiva também pela experiência de Joyce (nome fictício, tese 3), que fala sobre como o saber das travestis extrapola o saber sobre a anatomia e a ciência médica, quando conta: "Tomei hormônio da maneira que normalmente as meninas tomam por aí. Uma vai passando pra outra, uma aplica na outra... dessa forma assim! Desse jeito".

Joyce e Fernanda comunicam do saber construído à margem que se centraliza pelo caráter de continuidade de histórias, da existência de corpos-resistência, indicando a política via "desempenho da árdua tarefa de manterem [corpos] vivos"32(134). Legitimase pelo saber da experiência, apontando um espaço comum/comunidade. Esse saber também se caracteriza como uma ação educativa ${ }^{5}$, se passamos a entender que a comunicabilidade da experiência de um grupo reflete, simbólica e concretamente, na construção e manutenção de um saber compartilhado, demarcando epistemologias próprias.

Como falado, inúmeras são as trincheiras que mulheres (cis ou trans) e travestis encontram no caminho de permanência. Aqui questionamos se, para além da permanência escolar/universitária, poderíamos também falar em uma permanência em 'estado de saúde', ou melhor, em situações de vida que comuniquem da potencialidade em saúde.

Sobre isso, Fernanda fala: "Quando eu entrei na graduação, ficou mais fácil porque eu tinha um saber... ali eu construí um saber". Aqui, o termo 'quando' sinaliza a quebra da normalidade estabelecida por quem pensa a ciência, 
ou seja, uma possibilidade, e não uma garantia. Entende-se que a ciência é construída pela e na academia e que o saber construído é sempre sobre algo que, muitas vezes, escapa do habitual e do comum ${ }^{33,34}$.

Com essas narrativas, localizamos que as perspectivas que as ciências vêm assumindo pouco se responsabilizam com um compromisso social, pois não se comprometem com o retorno a seus sujeitos. O saber que se 'tem' (como posse) assume a quebra violenta, considerando a singularidade das lutas que perpassam gênero, corpo, classe social, regionalidade e raça. Pensamos que enquanto a saúde pública e a educação (também pública) não construírem espaços de garantia de direitos e de continuação do saber - inclusive porque são as teorias que conferem aos profissionais a tentativa de uma 'aproximação' prática -, mais ficarão distantes de seu público, conferindo a quebra do próprio sentido originário de saúde e educação $0^{35}$.

\section{Considerações finais}

Percebe-se um descompasso nos modos de produzir ciência, no Brasil, quando da incorporação de mulheres cis periféricas, mulheres trans e travestis, especialmente no que diz respeito a práticas de cuidado em saúde e educação. Nota-se que nem as jovens mulheres cis periféricas, que alcançam a universidade, nem as mulheres trans e travestis escrevem a respeito de suas próprias experiências, como apontado pelas três teses aqui analisadas. Confere-se, também, a falta de investimento material e imaterial para a permanência estudantil/universitária, o que fundamentaria alicerce para a inovação epistemológica e tecnológica de mulheres (cis e trans) e travestis.

Ainda que haja uma melhoria nos incentivos econômicos, no campo da educação, há insuficiência quando estamos falando em populações minoritárias/periféricas especialmente porque tais experiências são marcadas por profundas materializações, como violências e iniquidades em saúde.
A isso, soma-se a falta de comunicação de saberes produzidos pela própria população/ comunidade, atentando-se às singularidades que emanam de um povo/campo, o que caracteriza que, apesar de estar situado em um campo macro, revela-se como singular nestas, distante de generalizações para outros campos e experiências. Nesse sentido, infere-se que o Estado não só aniquila vidas como também produz, a partir de conhecimentos hegemônicos, a desigualdade de saberes a partir de um norte epistêmico profundamente enraizado no biopoder.

As experiências em serviços públicos de saúde, educação, assistência social e direitos humanos têm demonstrado a complexa disparidade encontrada entre mulheres cis periféricas, travestis e transexuais, quando comparadas a populações outras que não fazem parte desse recorte.

Fazem-se necessários posicionamentos outros a partir do Estado, assim como especificamente das instituições de saúde e educação. Se a população trans e travesti nem é considerada como existente, como pode chegar a produzir epistemologia? Se a população de mulheres cis periféricas com dificuldade chega e permanece no ensino superior, como pode produzir conhecimento? Sem que providências sejam tomadas com relação às trincheiras, a batalha seguirá existindo; e, no que tange à produção de conhecimento a respeito desses dois grupos, esta continuará sendo executada por terceiros, garantindo a perpetuação da exclusão.

\section{Agradecimentos}

A Irene Borges-Duarte, Henriette Tognetti Penha Morato e Marie Claire Sekkel, orientadoras das pesquisas aqui discutidas, por todo aprendizado, apoio e carinho. Chohfi LMS agradece à Universidade de Évora (Portugal), pela bolsa de mérito concedida e às colaboradoras de seu estudo; Melo JB agradece à Coordenação de Aperfeiçoamento 
de Pessoal de Nível Superior (Capes) e às colaboradoras de sua pesquisa; Souza PA agradece ao Conselho Nacional de Desenvolvimento Científico e Tecnológico (CNPq), bem como às ancestralidades travestis, que fizeram-na ser quem é.

\section{Referências}

1. Rago M. Michel Foucault e o Zoológico do Rei. In: Albuquerque Júnior DM, Veiga-Neto A, Souza Filho A, organizadores. Cartografias de Foucault. Belo Horizonte: Autêntica; 2011. p. 253-468.

2. Concilio IL, Amaral M, Silveira PM, organizadores. Transcidadania: Práticas e trajetórias de um programa transformador. São Paulo: Koinonia; 2017.

3. Leite JJ. Nossos corpos também mudam: a invenção das categorias "travesti" e "transexual" no discurso científico. São Paulo: Annablume; FAPESP; 2011.

4. Pelúcio L. Abjeção e desejo: uma etnografia travesti sobre o modelo preventivo de aids. São Paulo: Annablume; FAPESP; 2009.

5. Louro GL. O corpo educado: pedagogias da sexualidade. 3. ed. Belo Horizonte: Autêntica Editora; 2015.

6. Bento B. Transviad@s: gênero, sexualidade e direitos humanos. Salvador: EDUFBA; 2017.

\section{Colaboradores}

Chohfi LMS (0000-0003-0552-7517)*, Melo JB (0000-0003-3076-1217)* e Souza PA (00000001-6728-2004)* contribuíram igualmente para a elaboração do manuscrito.
*Orcid (Open Researcher and Contributor ID).
7. Laranjo THM, Soares CB. Moradia universitária: processos de socialização e consumo de drogas. Saúde Pública. 2006; 40(6):1027-1034.

8. Osse CMC. Pródromos e qualidade de vida de jovens na moradia estudantil da Universidade de Brasília. [dissertação]. Brasília, DF: Universidade de Brasília; 2008. 119 p.

9. Felippe JMS. Assistência estudantil no Instituto Federal Fluminense: possibilidades e limites para a permanência escolar e conclusão de curso. Educação. 2015; 14(1):145-155.

10. Fernandes NGO. A política de assistência estudantil e o Programa Nacional de Assistência Estudantil: o caso da Universidade Federal de Itajubá. [dissertação]. São Paulo: Universidade de São Paulo; 2012. $233 \mathrm{p}$.

11. Reis IM. Inclusão social no meio universitário: o discurso e a vivência cotidiana do estudante na EACH- 
-USP. [dissertação]. São Paulo: Universidade de São Paulo; 2015. 95 p.

12. Silveira MM. A Assistência Estudantil no Ensino Superior: uma análise sobre as políticas de permanência das universidades federais brasileiras. [dissertação]. Pelotas: Universidade Católica de Pelotas; 2012.137 p.

13. Vargas MLF. Ensino Superior, Assistência Estudantil e Mercado de Trabalho: um estudo com egressos da UFMG. [dissertação]. Belo Horizonte: Universidade Federal de Minas Gerais; 2008. 205 p.

14. Barreto WFA. O Programa de bolsas de manutenção acadêmica como estratégia da política de assistência do estudante da UFPE. [dissertação]. Recife: Universidade Federal de Pernambuco; 2003. 149 p.

15. Brasil. Decreto ${ }^{0} 7.234,19$ de julho de 2010. Dispõe sobre o Programa Nacional de Assistência Estudantil (PNAES). Diário Oficial da União. 19 Jul 2010.

16. Benjamin W. Magia e técnica, arte e política: ensaios sobre literatura e história da cultura. 8. rev. ed. São Paulo: Brasiliense; 2012.

17. Larrosa J. Tremores: escritos sobre a experiência. Belo Horizonte: Autêntica; 2018.

18. Silva EFG, Santos, SEB. Fenomenologia Existencial como caminho para pesquisa qualitativa em psicologia. Revista Nufen: Phenom. Interd. 2017; 9(3):110-126.

19. Cabral BE, Morato HTP. A questão de pesquisa como bússola: notas sobre o processo de produção de conhecimento em uma perspectiva fenomenológica existencial. In: Barreto CLBT, Morato HTP, Caldas MT, organizadores. Prática Psicológica na Perspectiva Fenomenológica. Curitiba: Juruá; 2013. p. 159-182.

20. Brasil. Ministério da Saúde. Mortalidade - 1996 a 2019, pela CID-10. DATASUS. [acesso em 2021 maio 14]. Disponível em: https://cutt.ly/pbCY3Y9.

21. Brasil. ONU Mulheres; Secretaria de Políticas para Mulheres; Instituto de Pesquisa Econômica e Aplicada. Retrato das Desigualdades de Gênero e Raça,
2018. [Brasília, DF]: Ipea. [acesso em 2020 jun 30]. Disponível em: https://cutt.ly/3bCTTob.

22. Almeida AB. Mortalidade de adolescentes e jovens adultos na Região Metropolitana de São Paulo, no período de 2000 a 2006. [dissertação]. São Paulo: Universidade de São Paulo; 2009. 48 p.

23. Associação Nacional de Travestis e Transexuais. Boletim n. 01/2021: Assassinatos contra travestis e transexuais em 2021. [Rio de Janeiro]: Antra. [acesso em 2021 maio 16]. Disponível em: https://cutt.ly/ FbCTSHb.

24. Dias H. Inclusão Social na USP. Jornal da USP Especial. 2016 set. [acesso em 2020 jun 30]. Disponível em: https://cutt.ly/ObCTILB.

25. Brasil. Constituição, 1988. Constituição da República Federativa do Brasil. Brasília, DF: Senado Federal; 1988.

26. Brasil. Instituto Brasileiro de Geografia e Estatística. Síntese dos Indicadores Sociais: Uma análise das condições de vida da população brasileira. [acesso em 2020 jun 30]. Disponível em: https://cutt.ly/hbCTP7l.

27. Morato HTP. Pedido, queixa e demanda no Plantão Psicológico: querer poder ou precisar? In: Anais VI Simpósio de Práticas Psicológicas em Instituição Psicologia e Políticas Públicas; 2006. Vitória: Universidade Federal do Espírito Santo; 2006.

28. Patto MHS. A produção do fracasso escolar: histórias de submissão e rebeldia. 4. ed. São Paulo: Casa do Psicólogo; 2015.

29. Souza BP. Orientação à queixa escolar: considerando a dimensão social. Psicol. Ciênc. Prof. 2006; 26(2):312319.

30. Beluche R. O corte da sexualidade: o ponto de viragem da psiquiatria brasileira no século XIX. São Paulo: Annablume; 2008.

31. Figueiredo LCM. Matrizes do pensamento psicológico. 20. ed. Petrópolis: Vozes; 2014. 
32. Kohn J. Introdução. In: Arendt H. A promessa da política. 2. ed. Rio de Janeiro: DIFEL; 2009. p. 7-44.

33. Ortega F, Zorzanelli R. Corpo em evidência: a ciência e a redefinição do humano. Rio de Janeiro: Civilização Brasileira; 2010.

34. Melo JB. O corpo que habito: possibilidades de compreensão para a experiência do corpo amputado. [dissertação]. Recife: Universidade Católica de Pernambuco; 2015. $131 \mathrm{p}$.
35. Morato HTP. Reflexões acerca da saúde: implicações para o desassossego humano contemporâneo. In: Dutra E, organizadora. O desassossego humano na contemporaneidade. Rio de Janeiro: Via Verita; 2018. p. 167-197.

Recebido em 31/08/2020

Aprovado em 05/05/2021

Conflito de interesses: inexistente

Suporte financeiro: Coordenação de Aperfeiçoamento de Pessoal

de Nível Superior - Brasil (Capes) - Código de Financiamento 001;

e Conselho Nacional de Desenvolvimento Científico e Tecnológico

- Brasil (CNPq) - Processo 140105/2021-2 